\title{
LOS CONECTORES DISCURSIVOS: SU EMPLEO EN REDACCIONES DE ESTUDIANTES UNIVERSITARIOS COSTARRICENSES
}

\author{
Carlos Sánchez Avendaño
}

\begin{abstract}
RESUMEN
En este artículo, se realiza un análisis pormenorizado del uso de los conectores discursivos por parte de estudiantes de primer ingreso a la universidad. En general, se encuentran dos características, en principio opuestas, con respecto a estas marcas: la subutilización de los recursos conectivos con que cuenta el español y la sobreutilización de un solo conector como representante de la noción discursiva que se quiere expresar. Además, se aporta evidencia para la hipótesis de la interferencia del registro oral sobre el escrito.

Palabras clave: conectores discursivos, registro escrito.
\end{abstract}

\begin{abstract}
In this article, a detailed analysis about the use of discourse connectors by university students is carried out. In general, two characteristics, apparently opposite, are found: the sub-use of the Spanish connective resources and the over-use of a single connector as representative of the discourse notion that the author wants to express. In addition, some evidence is brought forward for the interference of the oral register on the written register hypothesis.
\end{abstract}

Key words: discourse connectors, written register.

\section{Introducción}

Pese a tratarse de un tema de especial interés en la didáctica de la expresión escrita, los elementos cuya función consiste en conectar las distintas proposiciones en los textos no aparecen destacados en los libros publicados en Costa Rica hasta la fecha (cfs. Sánchez Avendaño 2004). Frente a temas tales como la ortografía, la corrección idiomática y el análisis gramatical tradicional, que ocupan la mayor cantidad de páginas, los conectores apenas si son mencionados, a veces y solo de paso, cuando se estudian las oraciones compuestas.

Carlos Sánchez Avendaño. Magister en Lingüística. Profesor de la Escuela de Filología y Lingüística de la Universidad de Costa Rica.

Recepción:21-2-05

Aceptación: 1-3-06 
Tampoco la investigación sobre las características y deficiencias en el manejo del registro escrito por parte de los costarricenses parece haberle prestado la debida atención al asunto. Quesada y Ramírez (1993) incluyen, dentro de sus indicadores para medir los problemas de redacción de los directores de centros educativos, el rubro denominado "mal uso de la conjunción", y entienden por esta un elemento invariable que enlaza y denota relación entre dos oraciones o palabras. Sus resultados exponen este problema como el último en porcentaje de aparición en la etapa de 1978 (solamente un caso, que representa el 0,28\%) y, para 1990, 1,76\% de los errores. No obstante, el corpus y el análisis de este trabajo resultan poco fiables cuando se observan los ejemplos consignados por las autoras ${ }^{1}$.

Rodino y Ross (1985), en su estudio acerca de los problemas de expresión escrita de los estudiantes de la UNED, tratan el asunto dentro de la sección de morfosintaxis, aunque únicamente comentan los problemas con las construcciones distributivas y comparativas, específicamente las siguientes: ya (sea)...ya/o..., tanto...cuanto..., uno/s...otro/s..., parte...parte..., una parte...otra..., no solo...sino..., $\tan / \operatorname{tanto...como...,~} \tan /$ tanto...que... Para estos autores, el problema yace en el empleo de estos nexos de forma inadecuada o incompleta (presentar solamente uno de los elementos de la relación), como en el siguiente ejemplo: "yo me voy a distraer ya sea oyendo música, contando chistes y también dando largos paseos" (correlación inadecuada). Rodino (1988) tampoco ahonda en el asunto, pero menciona que la yuxtaposición prevalece en los textos orales y escritos de los estudiantes universitarios estudiados por ella.

Como se puede apreciar, este aspecto merece entonces un análisis exhaustivo propio, por cuanto los conectores discursivos se proponen en los manuales de análisis del discurso y lingüística del texto como uno de los temas más relevantes para la cohesión discursiva. En nuestro país, Solano Rojas (1990) realizó un análisis pormenorizado de los nexos en el habla culta, pero nada se ha publicado sobre el empleo de estos recursos en el registro escrito. Nuestra impresión es que se trata de uno de los aspectos de manejo menos eficaz de la expresión escrita por parte del estudiantado universitario costarricense.

\section{La cohesión en los textos y los conectores discursivos}

Desde la perspectiva de la lingüística textual (de Beaugrande y Dressler 1997) que nos sirve de base para la investigación sobre las características y los problemas de expresión escrita de los estudiantes universitarios costarricenses, un texto (oral o escrito) es un acontecimiento comunicativo que se ciñe a determinadas normas de textualidad.

De todas ellas, las de más empleo en los textos didácticos y las que han merecido un mayor interés por parte de diversos investigadores son la coherencia y la cohesión, consideradas como fenómenos especialmente relacionados con la textura discursiva (Calsamiglia y Tusón 2002). Una posición bastante frecuente consiste en considerar que la coherencia guarda relación con el texto en un nivel subyacente o profundo, mientras que la cohesión es la manifestación superficial o patente de las relaciones discursivas entre los diversos componentes de un texto (Lozano et al 1999).

Ciertamente, la coherencia global de un texto no requiere de marcas explícitas para que el lector pueda establecer las relaciones lógico-semánticas, pues dichos lazos se llevan a cabo por medio de procesos cognoscitivos complejos tales como el establecimiento de causalidades necesarias ("El suelo está mojado", tuvo entonces que haberle caído algún líquido), el conocimiento de mundo de los hablantes ("Está resfriada. Se mojó ayer”; normalmente pensaríamos 
que está resfriada porque se mojó ayer) o el saber enciclopédico ("Los carros andan a alta velocidad. Hay que cruzar la calle rápido”), entre otros. Los participantes en una comunicación (interlocutores o lectores) son quienes, por consiguiente, infieren las relaciones entre los segmentos informativos, dado que estas se encuentran latentes en el discurso.

Sin embargo, existen en las lenguas índices de cohesión que se vislumbran como un recurso lingüístico altamente rico para conectar explícitamente diversos segmentos informativos de los textos, mediante la indicación de las relaciones semánticas que se quieren hacer evidentes entre ellos: recursos como las relaciones léxicas para mantener el referente textual (por ejemplo, emplear una palabra con sentido extensivo para comprender otras de sentido intensivo, como en el caso de 'problemas', que, en un determinado texto, podría englobar rubros como 'mal servicio de agua', 'apagones', 'falta de líneas telefónicas', 'bloqueo de desagües'), la puntuación como mecanismo de segmentación textual (cfs. Sánchez Avendaño en prensa) y partículas como 'sin embargo', 'por lo tanto' y 'además', entre muchas otras, que cumplen la función de establecer la cohesión en un texto.

La cohesión, entonces, establece en un nivel patente las relaciones entre distintos miembros de un discurso. Este estándar de textualidad mantiene un conjunto de conexiones en el interior de los textos para evidenciar las relaciones semánticas entre las porciones textuales que los componen. Desde la perspectiva cognoscitiva de Beaugrande y Dressler, la continuidad de los elementos que componen un texto permite mantener su estabilidad. Dicha continuidad "se basa, a su vez, en la suposición de que existe una relación entre los diferentes elementos lingüísticos que configuran el texto y la situación en la que el texto mismo se utiliza de hecho; o expresado en términos cognitivistas: cada elemento lingüístico es un instrumento eficaz para acceder a otros elementos lingüísticos" (de Beaugrande y Dressler 1997: 89). En este sentido, los mecanismos de cohesión cumplen la misión de lograr darle unidad al texto, de permitir que los elementos que lo componen se interpreten en relación unos con otros.

Dentro de estos mecanismos de cohesión textual, los llamados 'conectores discursivos' son los recursos que más evidentemente actúan como señalizaciones o indicios superficiales de los lazos semánticos profundos existentes entre porciones del texto. Estos elementos de conexión han recibido la atención de muchos lingüistas en los últimos años, quienes se han abocado a tratar de escudriñar su funcionamiento y a establecer tipologías, desde distintos puntos de vista y teorías (cfs. Portolés 2001, Martín Zorraquino 1999, Montolío 2001, Fraser 1999). El gran caudal de publicaciones que han surgido del interés por este tipo de elementos también ha producido un panorama bastante amplio, complejo y variopinto del fenómeno de la conexión textual, evidenciado sobre todo en la diversidad de nomenclaturas que pululan para referirse a estas marcas ${ }^{2}$.

Además, el asunto se complica cuando entran en juego las teorías lingüísticas de partida, las concepciones de qué constituye un conector y qué no (por restricciones sintácticas, semánticas o pragmáticas que establecen los investigadores para delimitar el objeto de estudio), el interés teórico o aplicado del estudio, etc. En vista de que este trabajo encuentra su razón de ser en un propósito meramente de diagnóstico, no nos detendremos en disquisiciones teóricas que, aunque interesantes y sumamente esclarecedoras, nos llevarían a perder de vista nuestro objetivo central: determinar los problemas de conexión en redacciones de estudiantes universitarios $^{3}$. Por esta misma razón, emplearemos aquí indistintamente los términos 'conector discursivo', 'nexo textual', 'conectivo', etc. para referirnos a elementos como 'no obstante', 'asimismo', 'por consiguiente', 'ya que' y otros de su misma naturaleza. 
La mayoría de los lingüistas que se han ocupado del tema (en especial, véase Fraser 1999 y Portolés 2001) coinciden en indicar que los conectores discursivos señalan una relación entre la interpretación de la porción informativa en la que aparecen y la porción anterior. No necesariamente deben aparecer al inicio del segmento, aunque por lo general lo introducen, como en el siguiente ejemplo:

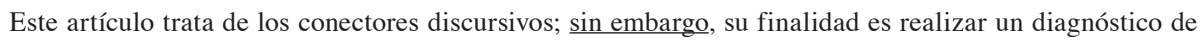
su empleo.

Claramente, se nota que la segunda porción informativa ${ }^{4}$ se relaciona con la primera en un sentido general de 'contrariedad', lo que luego llamaremos contraargumentación. La función que desempeña es mostrar explícitamente que, aunque se aborda el tema de los conectores, no se hace con el interés de teorizar al respecto, como podría suponerse de un artículo científico.

Un segundo aspecto -quizás el más fundamental- para comprender la naturaleza de estos conectores reside en su carácter de marcas de sentido de procesamiento, no conceptual (Fraser 1999, Portolés 2001). De acuerdo con esta perspectiva, los conectores actúan como señales de cómo debe procesarse una porción informativa en relación con el resto del texto y el contexto, pero carecen del significado léxico que poseen otras unidades (como 'lámpara', 'bonito' o ‘caminar'). En otras palabras, los conectores guían la realización de inferencias cuando se procesa un texto:

\footnotetext{
Los marcadores del discurso son unidades lingüísticas invariables, no ejercen una función sintáctica en el marco de la predicación oracional y poseen un cometido coincidente en el discurso: el de guiar, de acuerdo con sus distintas propiedades morfosintácticas, semánticas y pragmáticas, las inferencias que se realizan en la comunicación (Portolés 2001: 25-26).
}

Calsamiglia y Tusón (1999) realizan la distinción entre conectores metatextuales, los marcadores de operaciones discursivas y los conectores. Los conectores metatextuales contribuyen a la organización total del texto, no establecen una conexión semántica entre las proposiciones, sino que se orientan al desarrollo de la enunciación (inicio, desarrollo y conclusión). Estos pueden ser iniciadores (para empezar, antes que nada), distribuidores (por un lado, por otro), ordenadores (primero, en primer lugar), de transición (en otro orden de cosas), continuativos (entonces, en este sentido), aditivos (además, igualmente), digresivos (por cierto), espacio-temporales (antes, aquí, más abajo, seguidamente), conclusivos (en resumen), y finalizadores (en fin, por último).

Los marcadores que introducen operaciones discursivas particulares, por lo general, se ubican al principio del enunciado e indican la posición del hablante/escritor en relación con su proposición, o bien indican un tipo específico de tratamiento informativo. Entre otros, se encuentran: de expresión de punto de vista (en mi opinión, a mi juicio), de manifestación de certeza (es evidente que, es indudable que), de confirmación (en efecto, desde luego), de tematización (respecto a, a propósito de), de reformulación o aclaración (esto es, es decir), de ejemplificación (por ejemplo, a saber).

Los conectores, propiamente dichos, funcionan como relacionantes lógico-semánticos de los segmentos de información en el texto. Son de varios tipos: aditivos o sumativos (y, además), contrastivos o contraargumentativos (pero, en cambio), de base causal (causativos -por eso, 
porque-, consecutivos - de ahí que, pues-, condicionales - con tal de que, a menos que- y finales -para que, a fin de que-), temporales (cuando, de pronto), espaciales (enfrente, a lo ancho).

Esta es una tipología que, como se aprecia, privilegia tanto la posición del hablante como el carácter local o global del marcador. Otra tipología ${ }^{5}$, como la de Martín Zorraquino y Portolés (1999), se centra en las funciones discursivas que cumplen estas unidades:

Cuadro 1: Marcadores del discurso (Martín Zorraquino y Portolés 1999: 4081-4082)

\begin{tabular}{|c|c|c|}
\hline \multirow{3}{*}{$\begin{array}{l}\text { ESTRUCTURADORES DE } \\
\text { LA INFORMACIÓN }\end{array}$} & COMENTADORES & Pues, pues bien, así las cosas, etc. \\
\hline & ORDENADORES & $\begin{array}{l}\text { En primer lugar/en segundo lugar; por } \\
\text { una parte/por otra parte; de un lado/de } \\
\text { otro lado, etc. }\end{array}$ \\
\hline & DIGRESORES & $\begin{array}{l}\text { Por cierto, a todo esto, a propósito, } \\
\text { etc. }\end{array}$ \\
\hline \multirow[t]{3}{*}{ CONECTORES } & CONECTORES ADITIVOS & Además, encima, aparte, incluso, etc. \\
\hline & $\begin{array}{l}\text { CONECTORES } \\
\text { CONSECUTIVOS }\end{array}$ & $\begin{array}{l}\text { Por tanto, por consiguiente, por ende, } \\
\text { en consecuencia, de ahí, entonces, } \\
\text { pues, así, así pues, etc. }\end{array}$ \\
\hline & $\begin{array}{l}\text { CONECTORES } \\
\text { CONTRAARGUMENTATIVOS }\end{array}$ & $\begin{array}{l}\text { En cambio, por el contrario, por el } \\
\text { contrario, antes bien, sin embargo, no } \\
\text { obstante, con todo, etc. }\end{array}$ \\
\hline \multirow[t]{4}{*}{ REFORMULADORES } & $\begin{array}{l}\text { REFORMULADORES } \\
\text { EXPLICATIVOS }\end{array}$ & O sea, es decir, esto es, a saber, etc. \\
\hline & $\begin{array}{l}\text { REFORMULADORES DE } \\
\text { RECTIFICACIÓN }\end{array}$ & $\begin{array}{l}\text { Mejor dicho, mejor aún, más bien, } \\
\text { etc. }\end{array}$ \\
\hline & $\begin{array}{l}\text { REFORMULADORES DE } \\
\text { DISTANCIAMIENTO }\end{array}$ & $\begin{array}{l}\text { En cualquier caso, en todo caso, de } \\
\text { todos modos, etc. }\end{array}$ \\
\hline & $\begin{array}{l}\text { REFORMULADORES } \\
\text { RECAPITULATIVOS }\end{array}$ & $\begin{array}{l}\text { En suma, en conclusión, en definitiva, } \\
\text { en fin, al fin y al cabo, etc. }\end{array}$ \\
\hline \multirow[t]{2}{*}{$\begin{array}{l}\text { OPERADORES } \\
\text { ARGUMENTATIVOS }\end{array}$} & $\begin{array}{l}\text { OPERADORES DE REFUERZO } \\
\text { ARGUMENTATIVO }\end{array}$ & $\begin{array}{l}\text { En realidad, en el fondo, de hecho, } \\
\text { etc. }\end{array}$ \\
\hline & $\begin{array}{l}\text { OPERADORES DE } \\
\text { CONCRECIÓN }\end{array}$ & Por ejemplo, en particular, etc. \\
\hline \multirow{4}{*}{$\begin{array}{l}\text { MARCADORES } \\
\text { CONVERSACIONALES }\end{array}$} & DE MODALIDAD EPISTÉMICA & Claro, desde luego, por lo visto, etc. \\
\hline & DE MODALIDAD DEÓNTICA & Bueno, bien, vale, etc. \\
\hline & $\begin{array}{l}\text { ENFOCADORES DE LA } \\
\text { ALTERIDAD }\end{array}$ & Hombre, mira, oye, etc. \\
\hline & $\begin{array}{l}\text { METADISCURSIVOS } \\
\text { CONVERSACIONALES }\end{array}$ & Bueno, eh, este, etc. \\
\hline
\end{tabular}


En el registro escrito, la importancia de las marcas explícitas de relación lógico-semántica radica en la necesidad -y responsabilidad- de todo escritor de hacer evidentes en su texto las relaciones que desea dar a entender entre las porciones de información, en lugar de dejar que sea el lector quien deba reconstruir y suponer cuáles son esos lazos. En otras palabras, se trata ante todo de clarificar la intención y de facilitar el proceso de comprensión del texto. Como bien lo exponen Calsamiglia y Tusón (1999: 245), “en un estilo más elaborado y neutro [que el estilo expresivo], los conectores se expresan para evitar malentendidos y para asegurar una adecuada conexión".

En suma, los conectores son recursos sintáctico-semánticos que ayudan a presentar los lazos entre porciones de información de una manera más inequívoca; son elementos que facilitan el procesamiento del discurso. El modelo proposicional ${ }^{6}$ de procesamiento de los textos sostiene que, por lo general, de estos se recuerda el significado, pero no así su estructura morfosintáctica; se recuerda de un texto lo que se considera esencial, no su forma literal. En relación con lo anterior, lo que conviene rescatar aquí es, entonces, la necesidad de hacer patentes las relaciones entre esas proposiciones o enunciados, de manera que el procesamiento del discurso se vea beneficiado en términos de simplicidad y rapidez, y se demande del lector la elaboración de inferencias menos costosas, elementos deseables ambos en los textos cuya intención es servir en los ámbitos académicos. De ahí que esta preocupación aplicada haya llevado a autores como Montolío $(2000,2001)$ a dedicarse a estudiar los conectores del registro escrito y a elaborar materiales para su enseñanza.

Estos índices de cohesión cumplen con una función cognoscitiva (facilitar el procesamiento informativo del texto al fungir como guías de interpretación) y una función discursiva (proporcionar cohesión), aunque autores como Portolés (2001) son muy claros en afirmar que el objetivo de todo hablante/escritor consiste en comunicar su mensaje de la mejor forma, no en crear textos cohesionados.

La cohesión -y con ella los marcadores discursivos- no es más que un conjunto de mecanismos que facilita la labor de decodificación de los textos y su interpretación según las marcas que el autor pone en ellos para guiar diversos procesos de inferencia, de ahí que de Beaugrande y Dressler (1997) afirmen que, en definitiva, su empleo se trata de un detalle de cortesía del emisor para con el receptor, con el fin de facilitarle la decodificación eficiente del texto, así como una ayuda para el mismo emisor en su labor de organización y presentación de su discurso.

\section{Los conectores discursivos en redacciones de estudiantes universitarios}

En este apartado, nos ocuparemos del análisis de los marcadores empleados por una muestra de 60 estudiantes universitarios de primer ingreso, cuyas redacciones versan sobre algún problema de Costa Rica y sus posibles soluciones. El objetivo es cuantificar el uso y la variedad de empleo de estos recursos y detectar problemas en su utilización en textos de carácter académico. Asimismo, trataremos de evaluar una de las hipótesis mejor planteadas sobre los problemas de expresión escrita de los estudiantes universitarios de nuestro país, la cual postula que el déficit en el manejo del registro escrito por parte de esta población se debe a una interferencia de los patrones de su registro oral (Rodino y Ross 2001). Para dicho cometido, realizaremos una comparación de nuestros resultados con los datos de Solano (1990) sobre los nexos en el habla culta costarricense. 


\subsection{Los conectores lógico-semánticos}

Los conectores lógico-semánticos establecen un vínculo entre dos porciones informativas, de suerte que proporcionan una instrucción de cómo se ha de procesar (comprender y decodificar) la segunda porción en relación con la primera o viceversa. Son, por decirlo de otra manera, guías acerca de las inferencias que se deben producir sobre los dos fragmentos conectados.

\subsubsection{Conectores aditivos o sumativos}

Los conectores aditivos enlazan dos porciones informativas con la misma orientación discursiva. Dos fragmentos discursivos están coorientados cuando el segundo constituye una conclusión esperada del primero (Anscombre y Ducrot 1994, Portolés 2001); por ejemplo, si se dice: "La leche está agria. Hay que botarla", entendemos que hay que deshacerse de la leche porque está agria; esto es, asumimos que el primer enunciado es la causa para el segundo porque esta conclusión coincide con nuestros hábitos, nuestro conocimiento de mundo, con lo que consideramos "lógico" o de sentido común. En este caso, se dice que los dos enunciados están coorientados. Se puede agregar, por otra parte, que este tipo de conectores cumple con la función de indicar que la línea temática que se ha venido desarrollando continúa (Montolío 2001).

Montolío (2001) señala que existen, básicamente, dos tipos de conectores aditivos: aquellos que indican únicamente un tipo de suma, y los que -además de esta función-conllevan mayor fuerza argumentativa (en otras palabras, el conector indica que la porción informativa por él introducida implica mayor fuerza o impacto en la conclusión):

Cuadro 2: Conectores aditivos (adaptado de Montolío 2001: 143) ${ }^{7}$

\begin{tabular}{|l|l|}
\hline $\begin{array}{l}\text {-Conectores que introducen un } \\
\text { nuevo aspecto o punto del tema } \\
\text { que se está tratando pero sin valo- } \\
\text { rarlo desde el punto de vista argu- } \\
\text { mentativo }\end{array}$ & $\begin{array}{l}\text {-Conectores que introducen un } \\
\text { nuevo aspecto informativo del tema, } \\
\text { presentándolo como más fuerte } \\
\text { desde el punto de vista argumenta- } \\
\text { tivo que los aspectos anteriores }\end{array}$ \\
\hline $\begin{array}{l}\text { Asimismo } \\
\text { Igualmente } \\
\text { De igual/mismo modo/maneral } \\
\text { forma }\end{array}$ & $\begin{array}{l}\text { Además } \\
\text { Encima } \\
\text { Es más } \\
\text { Por añadidura } \\
\text { Incluso } \\
\text { inclusive }\end{array}$ \\
\hline
\end{tabular}

En el habla culta costarricense, el conector aditivo por excelencia parece ser ' $y$ ', el cual también puede asumir valores contraargumentativos ${ }^{8}$. En cuanto a su valor sumativo, el conector ' $y$ ' desempeña esta función en diversos niveles: relacionando palabras, frases, cláusulas y porciones textuales mayores (intervenciones en el habla y párrafos en la escritura). Ninguno de los trabajos sobre el español consultados considera el elemento ' $y$ ' como un conector del tipo que nos ocupa; no obstante, creemos que, al menos en algunas de sus funciones, se trata claramente de un elemento de enlace de porciones informativas coorientadas 9 . 
Como lo nota Solano (1990), el conector ' $y$ ' se caracteriza por expresar indicaciones de procesamiento muy diversas y disímiles entre sí. En el registro oral, pareciera comportarse como una marca de vinculación con funciones múltiples. En palabras de van Dijk (1993:114), “ $y$ puede denominarse un conectivo NEUTRO porque indica meramente que los hechos se relacionan, mientras que los otros conectivos denotan más específicamente el tipo de conexión”. Esto es, 'y' señala unión entre dos proposiciones, pero no indica con claridad el tipo de relación que se establece entre ellas; será labor del decodificador del texto, entonces, inducir cuál es la conexión lógico-semántica. Los siguientes ejemplos del habla culta costarricense pueden servir de muestra ${ }^{10}$ :

Y entonces mi mamá me dijo aquí en...en una calle aquí cercana, de San José que cruzara una calle. $\underline{Y}$ entonces yo crucé.

No, yo quería estudiar Medicina y entonces no había Escuela de Medicina (= pero)

Es un sueño que quise recrear en un cuento y no puedo (= pero)

A todas luces, por ende, el conector ' $y$ ' no es claro en cuanto a su valor de marca de procesamiento; por consiguiente, en un estilo cuidadosamente elaborado, propio de los textos académicos, en algunos casos debiera sustituirse por conectores de mayor explicitud semántica, cuando no se esté empleando como mero nexo dentro de las frases (por ejemplo, cuando une elementos de una serie).

En las redacciones examinadas, también el nexo 'y' presenta la frecuencia de aparición más alta. La selección de apariciones de 'y' que contabilizamos ${ }^{11}$ representa el $67 \%$ de los conectores aditivos utilizados ${ }^{12}$, como se aprecia en el cuadro 3 a continuación:

Cuadro 3: Conectores aditivos empleados por los estudiantes universitarios

\begin{tabular}{|l|c|c|}
\hline Conector & $\begin{array}{c}\text { Total de } \\
\text { apariciones }\end{array}$ & $\%$ \\
\hline y (e) & 125 & $67 \%$ \\
\hline también & 34 & $18 \%$ \\
\hline además & 23 & $13 \%$ \\
\hline (e) incluso/inclusive & 2 & $1 \%$ \\
\hline asimismo & 1 & $0,5 \%$ \\
\hline de esa misma manera & 1 & $0,5 \%$ \\
\hline Total & 186 & $100 \%$ \\
\hline
\end{tabular}


En general, el uso del conector 'y' no representa problemas serios de redacción; sin embargo, como se dijo, muchas veces se podría recurrir a otros elementos de cohesión más adecuados a un texto planificado, como se aprecia en los siguientes ejemplos:

\footnotetext{
Digo que este aspecto es por la cultura que tenemos puesto que el tico toma mucho, y no respeta el conducir (chofer designado). $\underline{Y}$ son sumamente irresponsables al conducir, corren mucho, $y$ no respetan la señalización
}

En el ejemplo anterior, las dos apariciones subrayadas de 'y' revelan claramente un fluir de ideas desordenadas; en otras palabras, se nota poca planificación de parte del autor, lo que correspondería más a un texto oral espontáneo. Debido a ello -creemos- se emplea este conector (perteneciente por excelencia al registro oral) en lugar de otros más apropiados como 'asimismo' en el primer caso. De hecho, esta injerencia de patrones propios de la oralidad en el registro escrito constituye una característica sobresaliente en el uso de los conectores en las redacciones analizadas, lo cual vendría a sumarse a la evidencia de la hipótesis de Rodino y Ross (1985). En general, el empleo “oralizado" de 'y' consiste en incluir este elemento como una seudocoordinación (cfs. Rodino 1988), una mera marca de continuidad del discurso, carente en realidad de un valor nexivo aditivo:

\begin{abstract}
La pobreza es la problemática que seguramente tiene las mayores propuestas de solución, ya que es uno de los problemas más grandes existentes en todo el mundo, pero aun así, es muy difícil encontrar una medida eficaz o al menos una que funcione ya que el pobre con el pasar del tiempo se convierte en una plaga, y digo plaga por el hecho que tiende a producir más pobres, en muchos casos y sino la mayoría, se da cuando se crean familias, y si bien el individuo no puede mantenerse por si mismo menos podrá con una responsabilidad paterna $\searrow$ por lo general estas personas ya sea por falta de educación, economía o planificación son de varios integrantes, lo que produce un incremento en la pobreza del país.

El país se ha visto afectado en este ámbito porque nuestro país esta marcado mundialmente por la prostitucion infantil y en los últimos días se han dado dos casos de abuso por parte de los padres a niñas menores de quince años las cuales por desgracia han quedado embarazadas $\unrhd$ aunque las dos niñas son de nacionalidad nicaragüense los casos se han dado en nuestro país lo cual nos esta dando fama de corrompedores de menores en el ámbito mundial.
\end{abstract}

También se presentan casos de empleo de 'y' con un valor no aditivo. En otras palabras, el autor podría haber recurrido a un conector con un valor semántico más claro con el fin de facilitarle al lector la labor de procesamiento, como en los siguientes ejemplos, en los que el valor de finalidad queda oscurecido:

\footnotetext{
Esto es una realidad muy preocupante que debe llamar la atención de todos los ciudadanos \ tratar de resolverlo.

Todos los conductores quieran o no deben de ir a efectuarse la revisión técnica $\unrhd$ aunque gasten mucho dinero arreglando su carro (aunque no sería muy buen beneficio para ellos), puedan transitar con calma.
}

En el siguiente caso ' $y$ ' tiene un valor contraargumentativo; no obstante, el sentido queda oscurecido por no haberse empleado un conector con esta función (como 'pero'). A todas luces, se trata de un ejemplo de mal uso de un conector, que a su vez implica un problema de cohesión y un obstáculo para la decodificación sencilla del texto: 


\begin{abstract}
Debemos de abrir los ojos y ver como nos estamos destruyendo y que las decisiones que se han tomado no han sido las correctas, hay que preocuparse por el bien común de todos, y desgraciadamente solamente nos importa el bienestar propio.
\end{abstract}

En el fragmento a continuación, 'y’ se usa con un valor consecutivo ('por lo tanto'):

(...) porque agresión sexual puede comenzar con otros abusos mas leves \\ debemos evitarlos y cuidar más a nuestros niños.

En suma, la apreciación de van Dijk de que se trata de un conectivo neutro, poco claro en su valor lógico-semántico, se aplica a muchos de los ejemplos de utilización de esta marca en las redacciones analizadas. En todo caso, de las 125 apariciones contabilizadas, se podría sostener que 24 corresponden a indicaciones imprecisas, interferencias del registro oral en el escrito o un definitivo uso inapropiado de este nexo. Por consiguiente, se aprecia una especie de empleo de recursos del registro oral informal en textos escritos formales como una guía poco clara de cómo se deben interpretar las porciones informativas unas en relación con las otras (v.g. propósito, adversación, consecución, etc.).

El segundo conector aditivo, en orden de frecuencia relativa de aparición, sería 'también' (18\%). En las redacciones analizadas, no parece presentarse ningún problema en el uso de este elemento, pues su valor es claramente sumativo y coorientado. La única observación que se podría realizar al respecto tiene que ver con el empleo de este nexo en un contexto discursivo en el que, muy probablemente, sería más adecuado otro conector aditivo con mayor fuerza argumentativa, en el sentido de Montolío (2001). 'También' simplemente actúa como una marca de adición, sin indicar el mayor o menor impacto de la porción informativa por él introducida; en este sentido, algunas veces no queda claro en las redacciones si se trata de una mera sumatoria o de la inserción de un elemento con mayor fuerza (al estilo de 'además'), como en el siguiente ejemplo:

\footnotetext{
Esto ya se ha hecho en el pasado [filmar películas en Costa Rica] pero no ha habido ninguna organización totalmente encargada de esto para que pueda decidir cuando es adecuado cobrarles a las compañías, ya que actualmente pagan muy poco para aprovecharse de la riqueza escénica de nuestro país. También es muy sabido que muchos estadounidenses de la tercera edad buscan países tropicales como Costa Rica para disfrutar de su jubilación, esto se puede aprovechar creando una organización con subsidiarios en Estados Unidos que desarrollen planes de viajes para estas personas al país y les ayuden a conseguir acomodamiento y varias otras cosas.
}

Precisamente, el tercer conector en orden de aparición sería 'además' (con sus correspondientes formas integradas sintácticamente 'además de' y 'además de que'). En este caso, entonces, se trata de una señal clara de la introducción de una porción informativa que, aunque aditiva, implica una mayor carga argumentativa:

Atendiendo a la definición, el pobre no puede alimentarse, tampoco vestirse ni educarse. Además no recibe atención médica adecuada ni tiene acceso a fuentes de trabajo, al tiempo que su vida afectiva y espiritual tiende a ser reducida.

Estudios realizados, demuestran que esta fobia [hacia las matemáticas] afecta el número de profesionales en las carreras técnicas, ya que los estudiantes huyen de las matemáticas; vitales en profesiones como la ingeniería o la arquitectura. Además, esta fobia hace que los estudiantes deban repetir sus cursos de matemáticca varias veces antes de aprobarlos. 
Debemos tomar una verdadera conciencia sobre los alcances de este problema y no quedarnos indiferentes. Ya que para combatir la drogadicción lo primero que hay que hacer es denunciar, dejando de lado el miedo, la pereza o el desinterés.

Además se debe apoyar a los centros de rehabilitación para personas adictas, porque muchas veces no tienen el dinero ni el personal suficiente, para ayudar a quienes de verdad desean salir de todo eso y superarse.

Además de los conectores 'y', 'también' y 'además', se encuentran en las redacciones los nexos 'e incluso', 'e inclusive', 'asimismo' (escrito, en realidad, de forma separada 'así mismo'), 'de esa misma manera'. Cada uno con una única aparición, lo cual indica que, con toda probabilidad, estamos ante un caso de subutilización de los recursos linguiísticos del registro escrito formal. Todo apunta a que los conectores aditivos empleados son, asimismo, los más recurrentes en el registro oral; por consiguiente, los nexos propios del registro escrito son escasamente explotados, como sería el caso de 'asimismo' o de 'inclusive':

\footnotetext{
(...) la necesidad de trabajar por los inmigrantes casi que los obliga a trabajar por menos, cuyo resultado es un desplazamiento de la mano de obra tica (que cobra los mínimos o más) dejando parte de la oferta sin trabajar. Así mismo los extranjeros toman los trabajos más básicos o menos remunerados desplazando a los ticos a la necesidad de competir por trabajos que requiere mejor educación o experiencia, lamentablemente no siempre tienen estos requisitos.
}

Muchas veces los padres de familia son los encargados de estigmatizar a las matemáticas basados en sus propias experiencias negativas, e inclusive se encargan de justificar los fracasos de los estudiantes.

\subsubsection{Conectores contraargumentativos}

Según la teoría de Ducrot y Anscombre (1994; Portolés 2001), así como existen enunciados coorientados (ver 3.1.1.), también se encuentran enunciados que indican que se debe interpretar lo contrario de lo que normalmente se esperaría de la orientación argumentativa. Así, cuando se dice "Tengo hambre. Voy a buscar algo que comer" sin ningún conector se entenderá, por lo regular, que la segunda porción informativa se debe interpretar como una consecuencia de la primera. En el caso de "Tengo hambre. No quiero comer nada", la vinculación semántica entre las dos porciones informativas resulta extraña, porque, precisamente, no muestran la misma orientación; diremos, entonces, que se hallan antiorientadas. Para este segundo tipo de dirección argumentativa, los hablantes usualmente recurrirían a alguna marca que ayudara a hacer más fácilmente comprensible (procesable) la información: ya no se trata de una relación causa-consecuencia, sino de mostrar que se debe entender lo opuesto de lo habitual, como en "Tengo hambre, pero no quiero comer nada". Este tipo de operaciones se conocen como contraargumentación.

Se trata, en todo caso, de guiar también la realización de inferencias: "Tengo hambre, pero no quiero comer nada" implica que lo esperable es que, si alguien tiene hambre, quiera comer algo. Las inferencias producidas a partir de estas relaciones nos proveen información acerca del conocimiento que poseen los hablantes de cómo funciona regularmente el mundo (como en el ejemplo comentado), sobre ciertas vinculaciones culturales ("Es pobre pero honrado" implica que, normalmente, no se espera que un pobre se comporte de esta manera, lo que, sin lugar a dudas, constituye un prejuicio de nuestra sociedad), y sobre relaciones establecidas 
particularmente por un hablante ("No tengo suerte, pero me casé con Lucrecia”, lo que significa que, para el hablante, el haber contraído matrimonio con Lucrecia constituye un acto de buena suerte).

Montolío (2001) agrupa los conectores contraargumentativos en cuatro categorías, según criterios semánticos y de integración sintáctica (ver cuadro 4). Según criterios sintácticos, esta autora habla de conectores integrados y conectores parentéticos. Los integrados se hallan unidos a la estructura de la oración mediante algún nexo (generalmente 'que', 'de' y 'a'); por su parte, los parentéticos se insertan dentro de la estructura sintáctica sin ningún tipo de enlace de integración y tienen, por ello, mayor movilidad.

La diferencia fundamental entre los dos primeros subgrupos tiene que ver con la fuerza argumentativa; en otras palabras, cuál de las dos porciones informativas ligadas por el conector se marca como de mayor peso para llegar a una conclusión. Los conectores del grupo (i) muestran que la porción en la que aparecen tiene una fuerza menor que el otro segmento. Por el contrario, los conectores de (ii) poseen mayor fuerza argumentativa, indican que la proposición que introducen es la de mayor relevancia y, por lo tanto, la guía a una conclusión. Compárense los siguientes ejemplos: en $a$. se nota cómo 'estar enfermo' es una razón que le impide al hablante asistir a la fiesta; por el contrario, en $b$. el hecho de 'estar enfermo' no es causa suficiente para no ir.

a. Quiero ir a la fiesta, pero estoy enfermo.

b. Quiero ir a la fiesta, aunque estoy enfermo.

Cuadro 4: Conectores contraargumentativos (Montolío 2001: 49)

\begin{tabular}{|c|c|c|c|}
\hline $\begin{array}{l}\text { (i) expresiones conectivas } \\
\text { como aunque, a pesar de } \\
\text { (que), pese a (que) y si } \\
\text { bien, de las que aunque } \\
\text { es el conector prototípico } \\
\text { y que coinciden en estar } \\
\text { integradas entonativa y } \\
\text { sintácticamente en la ora- } \\
\text { ción }\end{array}$ & $\begin{array}{l}\text { (ii) conectores como pero, } \\
\text { sin embargo, no obstan- } \\
\text { te, ahora bien, con todo, } \\
\text { aun así o a pesar de todo, } \\
\text { grupo del que pero es el } \\
\text { representante paradigmá- } \\
\text { tico. Nótese que a excep- } \\
\text { ción de la conjunción } \\
\text { pero, todos los demás } \\
\text { elementos incluidos en } \\
\text { este subgrupo presentan } \\
\text { carácter parentético }\end{array}$ & $\begin{array}{l}\text { (iii) un tercer grupo está } \\
\text { formado por conectores } \\
\text { integrados en la oración } \\
\text { tales como mientras } \\
\text { que, en tanto que y sino } \\
\text { que, y, también, por los } \\
\text { correspondientes paren- } \\
\text { téticos en cambio, por el } \\
\text { contrario y antes bien. } \\
\text { Todos ellos comparten } \\
\text { un significado básico de } \\
\text { "corregir" en el segundo } \\
\text { miembro algún aspecto } \\
\text { de lo formulado en el pri- } \\
\text { mero. }\end{array}$ & $\begin{array}{l}\text { (iv) el cuarto y último } \\
\text { subgrupo está compues- } \\
\text { to por los conectores de } \\
\text { todas formas, de todas } \\
\text { maneras y de todos } \\
\text { modos. Se caracterizan } \\
\text { por el hecho de que, a } \\
\text { pesar de no ser propia- } \\
\text { mente contraargumenta- } \\
\text { tivos, aparecen en nume- } \\
\text { rosas ocasiones con un } \\
\text { valor similar. Todos ellos } \\
\text { coinciden en minimizar } \\
\text { o cancelar la relevancia } \\
\text { discursiva anterior y anu- } \\
\text { larlo (sic) para la prose- } \\
\text { cución del discurso. }\end{array}$ \\
\hline
\end{tabular}

En suma, los conectores contraargumentativos presentan el miembro textual en el que aparecen como una conclusión atenuada o como un inconveniente fuerte que se podría desprender del otro fragmento discursivo. 
En el habla culta costarricense, el nexo contraargumentativo de tipo adversativo por excelencia es 'pero', con un total de 71,9\% de las apariciones de los nexos de este tipo. De los conectores de tipo concesivo, sobresale en frecuencia de uso 'aunque'. En las redacciones estudiadas, 'pero' se emplea el 57\% de las veces, seguido por 'sino' (13\%) y por 'aunque' (9\%). Si bien la variedad de conectores de este tipo empleados es mayor que en el caso de los aditivos, nuevamente sobresale la subutilización de los conectores propios del registro escrito, frente a la abundante aparición de los nexos comunes tanto al registro oral como al escrito. El siguiente cuadro resume la frecuencia de aparición de los conectores encontrados:

Cuadro 5: Conectores contraargumentativos encontrados en las redacciones examinadas

\begin{tabular}{|c|c|c|}
\hline Conector & $\begin{array}{c}\text { Total de } \\
\text { apariciones }\end{array}$ & $\%$ \\
\hline pero & 98 & $57 \%$ \\
\hline $\operatorname{sino}$ & 23 & $13 \%$ \\
\hline aunque & 15 & $9 \%$ \\
\hline sin embargo & 7 & $4 \%$ \\
\hline aún así & 5 & $3 \%$ \\
\hline no obstante & 5 & $3 \%$ \\
\hline si bien & 5 & $3 \%$ \\
\hline mas & 3 & $2 \%$ \\
\hline más bien & 4 & $2 \%$ \\
\hline a pesar de (que) & 3 & $2 \%$ \\
\hline ahora bien & 1 & $0,5 \%$ \\
\hline pero sin embargo & 1 & $0,5 \%$ \\
\hline pese a & 1 & $0,5 \%$ \\
\hline más aún & 1 & $0,5 \%$ \\
\hline Total & 172 & $100 \%$ \\
\hline
\end{tabular}

En cuanto al empleo apropiado de este tipo de conexión, es precisamente en el caso del nexo 'pero' en el que se notan mayores problemas. Por un lado, nuevamente se pueden 
encontrar casos de transferencia de patrones de la oralidad en la escritura; así, 'pero' en ocasiones realmente no introduce una objeción, sino que cumple un papel discursivo distinto, como servir de marca formal de continuación o mostrar la posición incrédula o molesta del hablante:

\footnotetext{
En cuanto a la madre, que si no decide abortar a su hijo poniendo en peligro hasta su vida misma, decide tenerlo, pero que grado de afectividad irá a recibir el pequeño durante su niñez

Para estos casos se deben crear centros especializados de ayuda para niños o jóvenes en estas situaciones, pero que de verdad se haga algo para ayudarlos ya sea enseñándoles algún oficio o empleándolos en algún lugar.
}

Por otra parte, el problema más grave tendría relación más bien con indicaciones de procesamiento discursivo oscuras o inapropiadas. Por ejemplo, se encuentran casos en los que en realidad no hay una operación contraargumentativa, por lo que la inserción de un nexo con este valor puede complicar la lectura del texto:

\footnotetext{
Ante este problema se ha visto un leve avance por parte de autoridades para combatir las drogas y la drogadicción en Costa Rica, pero las drogas es un problema muy difícil de solucionar. Pero ¿estaremos peleando la batalla en la forma adecuada?
}

Otro problema común es el uso de 'pero' en lugar de otro conector contraargumentativo con un valor más apropiado a las intenciones del texto y la información que desea indicar el autor:

La violación es una de las razones por las que niñas y jóvenes quedan embarazadas, pero en la mayoría de los casos es la mala información que se recibe en la casa.

En el caso anterior, partiendo de que en un texto planificado el estilo debería estar más depurado, quizás hubiera sido más efectivo introducir la primera porción discursiva con un conector débil con el fin de enfatizar la debilidad del primer argumento frente a la fuerza del segundo, según parece desprenderse de la posición del autor, en cuyo caso el fragmento quedaría: "Aunque la violación es una de las razones por las que las niñas y jóvenes quedan embarazadas, en la mayoría de los casos es la mala información que se recibe en la casa (la causante del problema)". Se trata, simplemente, de planear cuál es la mejor forma de presentar las porciones textuales de manera que los recursos sean más eficaces y efectivos.

Este empleo de un conector contraargumentativo de un tipo cuando sería más efectivo utilizar otro para los propósitos de la exposición-argumentación afecta también otros nexos. En el siguiente ejemplo, por el lugar en que aparece 'aunque' y en aras de una mejor indicación de la fuerza argumentativa, sería más apropiado recurrir a 'sin embargo':

\footnotetext{
[la globalización] ha sido definida como la causa de desnacionalización de los mercados, las leyes y la política en el sentido de interrelacionar pueblos e individuos por el bien común. Aunque puede ser discutible que tenga esa finalidad.
}

En el caso de 'si bien', a pesar de su poca frecuencia de aparición, se encuentran dos empleos inapropiados de este nexo y un error bastante sui géneris, cual es la inversión de sus 
elementos constitutivos (el estudiante escribió 'bien si’). La impropiedad en el uso de este nexo guarda relación con problemas en cuanto a su papel de guía de procesamiento; en otras palabras, en el contexto discursivo en el que aparece, este conector no contribuye a la interpretación del mensaje, sino que, por el contrario, la oscurece, bien porque hace pasar por operación contraargumentativa algo que no lo es, bien porque se usa en conjunción con otros nexos, lo que resulta en una decodificación dificultosa de la información:

La pobreza es la problemática que seguramente tiene las mayores propuestas de solución, ya que es uno de los problemas más grandes existentes en todo el mundo, pero aun así, es muy difícil encontrar una medida eficaz o al menos una que funcione ya que el pobre con el pasar del tiempo se convierte en una plaga, y digo plaga por el hecho que tiende a producir más pobres, en muchos casos y sino la mayoría, se da cuando se crean familias, y si bien el individuo no puede mantenerse por si mismo menos podrá con una responsabilidad paterna y por lo general estas personas ya sea por falta de educación, economía o planificación son de varios integrantes, lo que produce un incremento en la pobreza del país.

Es necesario analizar la razón o razones por las que ocurre esta situación en nuestro país. Para esto primero hay que ver la condición socioeconómica de las familias costarricenses, la pobreza tiene altos índices en el país y este es uno de los principales causantes de la salida de las aulas. Si bien es cierto se supone que los hijos de personas con alta posición económica pueden estudiar, pero hay los casos en que estos no estudian porque los padres les pueden dar todo, además los hijos piensan que los van a mantener siempre.

También el conector 'no obstante' puede presentarse en contextos discursivos inapropiados, especialmente porque no contribuye a la decodificación simple del texto (razón de ser de los conectores) al servir de guía de procesamiento de una porción informativa antiorientada con respecto a la anterior. Por el contrario, su uso confunde, puesto que en realidad no existe tal antiorientación, sino otro tipo de operación: aditiva en el primer caso y causativa-consecutiva en el segundo:

\footnotetext{
Esto [la pobreza] es algo que afecta al país de una manera bastante grave, ya que directa o indirectamente, podría ser la causa de la gran mayoría de los problemas del país; ya mencioné que de manera directa trae delincuencia, violencia, drogas y prostitución, e indirectamente influye mucho en el surgimiento económico del estado, porque si un veinte porciento de la población se encuentra desempleada, el nivel de producción obviamente no es tan alto y entonces el país va desarrollándose de una manera casi nula. No obstante, en nuestro país el dinero en muchas ocasiones se encuentra en pocas manos, trayendo a la superficie más pobreza.
}

Como ya se dijo, en el siguiente ejemplo 'no obstante' no une argumentos contrapuestos, sino que, más bien, dada la forma en que el autor presenta las porciones textuales, el sentido va dirigido a establecer una consecuencia desprendida de una comparación, por lo cual la operación es consecutiva ('por lo tanto'):

\footnotetext{
Primeramente, es necesario emitir una comparación entre los intereses de uno mismo como individuo y los de la colectividad. El ser humano desea libertad, igualdad y prosperidad para mantener una buena convivencia con los demás. Por otra parte, la colectividad busca el respeto de las leyes, la socialización de la producción, la creación y conservación de buenas relaciones con otras colectividades. No obstante, es imperante un equilibrio entre ambos términos, evaluado en aspectos como las mismas leyes (...).
}

Por último, de las tres veces en las que aparece 'mas', dos de ellas se pueden clasificar como inapropiadas. Sobre todo, más que un error propiamente dicho, se trata de la utilización de este conector en un contexto en el que, por su ubicación (inicio de enunciado o de 
párrafo), sería más claro recurrir a 'no obstante' o 'sin embargo', en especial por la confusión que conlleva el que se entienda como su homófono 'más':

\begin{abstract}
(...) Toda persona puede ayudar a los demás de muchas maneras, ya sea colaborando al laborar para una determinada empresa o la creación de las mismas, al proveer beneficios personales y comunales a aquellos que requieren de un empleo. Mas, no se debe pensar únicamente en el dinero, sino también en el desarrollo de proyectos de trabajo voluntario (...).

Las zonas norte y sur de nuestro país sufrierón de efectos climáticos que imposibilitaban las jornadas completas, así como la señalización efectiva. Esta última la comprobé en un viaje a Jacó que realizé recientemente.
\end{abstract}

Mas de nada sirve la crítica sin buscar soluciones (...).

Por último, vale la pena recalcar la bajísima frecuencia de aparición (y, por lo tanto, de uso) de algunos conectores de este tipo. Como se aprecia en el cuadro 5, los conectores como 'a pesar de', 'pese a', 'más aún', 'ahora bien' apenas se reportan una vez. Los dos primeros son un tipo de alternante de 'aunque', con lo que se ve que, prácticamente, el único conector de su clase que se emplea en las redacciones es precisamente este último. Por lo tanto, se nota una subutilización de la variedad de elementos comprendidos en el repertorio de los conectores contraargumentativos en español.

\title{
3.1.3. Conectores de base causal
}

Autores como Portolés (2001) y Montolío (2001) no incluyen dentro de sus disquisiciones sobre los conectores a los causativos ni de finalidad, sino que se refieren únicamente a los consecutivos; en contraste, Calsamiglia y Tusón (2002) proponen una categoría que englobaría los tres tipos mencionados: los conectores de base causal (causativos, consecutivos y finales). Por conveniencia expositiva, nos ceñimos, entonces, a la clasificación propuesta por estas últimas lingüistas.

\subsubsection{Conectores consecutivos}

Los conectores consecutivos cumplen la función de indicar que la porción informativa en la que aparecen se debe procesar como una consecuencia de la porción anterior. El siguiente cuadro, tomado de Montolío (2001), nos muestra la variedad de conectores de este tipo:

\section{Cuadro 6: Conectores consecutivos (Montolío 2001: 102)}

\begin{tabular}{|l|l|}
\hline $\begin{array}{l}\text { Conectores conclusivos “integrados en la oración” } \\
\text { (que presentan la conjunción que) }\end{array}$ & Conectores conclusivos de tipo “parentético" \\
\hline - así que & - por ello/eso \\
- de manera que, de modo que & - por ese/tal/dicho motivo/razón/causa \\
- por lo que & - por (lo) tanto \\
- de ahí (que) & - en consecuencia \\
& - por consiguiente \\
& - por ende \\
& - pues \\
& - así pues \\
\hline
\end{tabular}


En cuanto al habla culta costarricense, en este punto es difícil elucidar cuál es el conector consecutivo de mayor uso, por cuanto Solano (1990) trata en la misma sección los conectivos consecutivos, ilativos y continuativos. En todo caso, parece ser el conector 'entonces' el más empleado en el corpus por ella analizado. Otros conectores como 'por consiguiente', 'por lo tanto' y 'por lo que' muestran una baja frecuencia de uso.

El cuadro 7 muestra cuáles son los nexos consecutivos encontrados en el corpus de redacciones estudiado:

\section{Cuadro 7: Conectores consecutivos encontrados en el corpus}

\begin{tabular}{|l|c|c|}
\hline Conector & $\begin{array}{c}\text { Total de } \\
\text { apariciones }\end{array}$ & \% \\
\hline por lo que & 8 & $20,5 \%$ \\
\hline así (que) & 8 & $20,5 \%$ \\
\hline por eso & 7 & $19 \%$ \\
\hline por esta razón & 4 & $10 \%$ \\
\hline por (lo) tanto & 3 & $7,5 \%$ \\
\hline entonces & 2 & $5 \%$ \\
\hline de ahí que & 2 & $5 \%$ \\
\hline de manera que & 1 & $2,5 \%$ \\
\hline por ende & 1 & $2,5 \%$ \\
\hline como consecuencia & 1 & $2,5 \%$ \\
\hline por ello & 1 & $2,5 \%$ \\
\hline es por eso que & 1 & $2,5 \%$ \\
\hline Total & 39 & $100 \%$ \\
\hline
\end{tabular}

Lo primero que salta a la vista es el escaso uso de este tipo de conexión, a pesar de que se trata de textos expositivo-argumentativos, en los cuales se debía hablar de un problema, sus causas, consecuencias y posibles soluciones. No se nota, empero, una utilización inadecuada de este tipo de conectores, a no ser por un caso de la partícula 'que' (no contabilizada). Se trata de un empleo que conlleva una decodificación difícil de la información, por cuanto no es sencillo entrever el valor consecutivo de la partícula dada la construcción sintáctica del párrafo: 
En todo caso, llama la atención, nuevamente, que únicamente tres nexos representan más de la mitad de los usos consignados; en este caso, 'por lo que', 'así (que)' y 'por eso'; es decir, reaparece el problema de la poca variedad de recursos empleados. A continuación se presentan algunos ejemplos de conexión consecutiva:

\begin{abstract}
En poco tiempo se ha demostrado que el índice de este tipo de abuso ha aumentado considerablemente, alertando a la sociedad de una manera alarmante; cabe resaltar que generalmente las niñas que son agredidas pertenecen a clases marginales donde el nivel económico y educativo es muy bajo y por tanto sus ciudadanos resultan de alguna manera, incapaces de tener alguna noción sobre el daño que puede causar esta situación.
\end{abstract}

Además una considerada parte de ellas han sido violadas y ultrajada su inocencia, quedando embarazadas en el acto criminal y despiadado, por lo que muchos de esos bebés por nacer son niños no deseados por su madre o por ambos padres según el caso y las circunstancias de cada situación.

Actualmente podemos observar que desgraciadamente el sistema funciona de una forma muy equivocada, de ahí se da la formación de los diferentes niveles sociales.

En el siguiente fragmento, se aprecia el uso del conector parentético 'por ende' incrustado en la porción informativa que le corresponde, no al inicio de esta. Este empleo está casi completamente ausente en las redacciones examinadas, pese a que la movilidad de los conectivos es una estrategia discursiva del español que se visualiza como de gran expresividad y que podría implicar cierta madurez en el uso de los recursos del registro escrito:

\begin{abstract}
La corrupción se ha vuelto cada día más y más una costumbre, una tradición de la clase política costarricense porque, ¿cómo podrían ellos ser capaces de luchar contra la corrupción cuando ésta les ayuda tanto? Es así como nace este complicado problema moral en las mentes y supuestos corazones de aquellos que toman el dinero de quienes tienen poco o muy poco y lo convierten en su fortuna personal. Esta tiranía y arrogancia es la que provoca que el pueblo ya no tenga la misma confianza en sus gobernantes y demás personas que manejan al país que tenía antes.
\end{abstract}

Se presentan por ende nuevos problemas relacionados con el descontento del pueblo como la significativa abstinencia en las elecciones, la evidente posición defensiva en los costarricenses ante las clase política y la constante negativa del pueblo costarricense ante el pago de impuestos debida principalmente al temor (...).

\title{
3.1.3.2. Conectores causativos
}

Los conectores causativos introducen la noción de causa en la vinculación de dos porciones informativas. Como lo nota claramente Montolío (2001), en el fondo se trata de la misma relación lógica causa-efecto que encontramos en los conectores consecutivos. La diferencia estriba, fundamentalmente, en la relación que se priorice o focalice por medio del conector. Así, dos porciones informativas se pueden presentar igualmente como causa o como consecuencia según sea alguna de las dos la conexión que se quiera hacer patente, como sucede en los siguientes ejemplos:

a. Tomé café, porque tenía sueño (consecuencia-causa, se destaca la causa)

b. Tenía sueño, por eso tomé café (causa-consecuencia, se destaca la consecuencia) 
Precisamente por esta ligazón entre la conexión causal y consecutiva, a veces es difícil establecer clasificaciones fijas sobre el valor de un conector. Calsamiglia y Tusón (2002) etiquetan como causales los siguientes elementos: a causa de ello, por eso, porque, pues, puesto que, ya que, dado que, por el hecho de que, en virtud de, gracias a. Para estas autoras, son conectores consecutivos los siguientes: de ahí que, pues, luego, por eso, de modo que, de ello resulta que, así que, de donde se sigue, así pues, por (lo) tanto, de suerte que, por consiguiente, en consecuencia, en efecto, entonces. Por su parte, para Montolío (2001), un nexo como 'por eso' se clasifica como consecutivo. Por todo ello, en este apartado solamente tratamos los conectores con un claro valor causal al estilo de 'porque', lo que implica que presentan la noción de que la porción informativa que sigue debe interpretarse como una causa; al contrario de elementos como 'por eso', que en realidad señalan que la causa es un fragmento discursivo anterior al que introducen.

De acuerdo con el análisis de Solano (1990), el conector causal por antonomasia en el habla culta costarricense sería 'porque' (96,43\%), seguido muy de lejos por 'ya que' (1,95\%), 'puesto que' $(0,97 \%)$, 'pues' $(0,87 \%)$ y 'dado que' $(0,16 \%)$. El cuadro 8 muestra los conectores contabilizados y analizados presentes en las redacciones en estudio:

Cuadro 8: Conectores causativos en las redacciones

\begin{tabular}{|l|c|c|}
\hline Conector & $\begin{array}{c}\text { Total de } \\
\text { apariciones }\end{array}$ & $\%$ \\
\hline ya que & 60 & $48 \%$ \\
\hline porque & 40 & $32 \%$ \\
\hline debido a (que) & 7 & $5,5 \%$ \\
\hline pues & 7 & $5,5 \%$ \\
\hline puesto que & 4 & $3,5 \%$ \\
\hline gracias a & 2 & $1,5 \%$ \\
\hline a causa de & 2 & $1,5 \%$ \\
\hline como & 2 & $1,5 \%$ \\
\hline dado que & 1 & $1 \%$ \\
\hline Total & 125 & $100 \%$ \\
\hline
\end{tabular}

De nuevo, nos encontramos con la situación en la que se recurre básicamente a dos conectores para expresar la relación lógico-semántica entre diversas porciones discursivas, en este caso el vínculo causativo.

Como se aprecia del conteo del cuadro 8, en esta oportunidad difieren los datos entre el registro oral y el registro escrito. En el primero, de acuerdo con Solano (1990), el conector más utilizado es 'porque'. En las redacciones estudiadas, 'porque' también es uno de los más frecuentes (32\%), pero se encuentra bastante por debajo de 'ya que' (48\%), el cual muestra una frecuencia de aparición de sólo 1,95\% (doce ocurrencias) en el habla culta costarricense.

Cabe establecer un parangón entre este fenómeno de sobreutilización del conector 'ya que' -el cual aparece poco en el habla- y lo que Rodino y Ross (1985) sugieren con respecto al empleo indiscriminado de las formas 'el cual/la cual/los cuales/las cuales' en los textos escritos analizados por ellos. Para estos lingüistas, es notorio el problema del abuso de estos pronombres en las redacciones de los universitarios estudiados, pero, a diferencia del resto de 
las deficiencias e impropiedades encontradas por ellos, afirman que no se trata de una interferencia del código oral sobre el escrito ${ }^{13}$, pues 'el cual' no es un elemento que se dé típicamente al hablar, sino, sobre todo, en la escritura. Para ellos, por ende, se trata de un tipo de ultracorrección: "Sobre-extensión de una norma o rasgo prestigioso a contextos linguiísticos en los cuales jamás la usarían los hablantes nativos (naturales, propios) de esa norma" (Rodino y Ross 1985: 139). Es decir, el abuso de 'el cual' de debe a que el escritor inexperto asocia su empleo con una mayor formalidad y un mayor prestigio de esta forma por sobre 'que'.

Consideramos que sucede exactamente lo mismo con el conector 'ya que': por alguna razón, existe una especie de conciencia de que 'porque' es un elemento altamente frecuente en la oralidad, por lo cual se recurre, al escribir, a otro elemento afín en cuanto a su función y significado, lo que ha llevado a la equiparación de la expresión de la causa en la escritura con el conector 'ya que' en nuestro medio, según se desprende de los datos analizados ${ }^{14}$.

Así, por ejemplo, en una de las redacciones (por lo demás, una de las mejor escritas), aparecen cinco conexiones causales, todas ellas introducidas con 'ya que'15.

\footnotetext{
Estudios realizados, demuestran que esta fobia afecta el número de profesionales en las carreras técnicas, ya que los estudiantes huyen de las matemáticas (...)

Esta carencia también es otro factor que afecta este proceso de aprendizaje, ya que el proceso demanda profesionales capacitados (...)

Esta problemática no presenta una solución inmediata, ya que el problema se ha gestado durante bastantes años (...)

Este proceso requiere de varios años, ya que la educación de un pueblo no puede modificarse de la noche a la mañana (...)

Yo como futuro ingeniero civil estoy conciente de mi compromiso con el desarrollo del país y con la solución de este problema, ya que nos concierne a todos.
}

Aparte de la subutilización de los recursos nexuales para la expresión de la causa, este tipo de conectores no parece representar mayor problema para los estudiantes universitarios, como se aprecia en los siguientes fragmentos:

\footnotetext{
(...) suena soñador e imposible pero el objetivo primordial es cambiar la mentalidad de las personas con el tiempo, pues, si fue posible inculcarles ese odio, será realizable desarraigarlo (...)

Cuando se trata de construir o arreglar una carretera en Costa Rica es un proceso muy largo y difícil, en el sentido de que el gobierno dura mucho tiempo aceptando el plan de construción, me refiero a unos varios años, y cuando por fin lo acepta el plan ya esta desactualizado con la sociedad actual, dado que los automoviles en circulación aumentan considerablemente cada año.

Uno de los grandes problemas que se tuvieron en este año en curso fue la fecha de inicio de clases, puesto que la población de este país no sabía si se entraba en febrero o en marzo, debido a la falta de fondos del estado para pagar a sus profesores y además que es un convenio centroamericano.
}

\subsubsection{Conectores de propósito o finalidad}

Ni Portolés (2001) ni Montolío (2001) se ocupan de estos marcadores discursivos, por lo cual seguimos el criterio de Calsamiglia y Tusón (2002) para incorporarlos en este grupo. Según estas autoras, los conectores de finalidad "introducen la causa como meta o propósito que se persigue" (Calsamiglia y Tusón 2002: 248) y dan la siguiente lista: para que, a fin de que, con el propósito/objeto de, de tal modo que. Nuevamente, es díficil precisar cuáles son 
los conectores de este tipo en el habla culta costarricense, por cuanto Solano (1990) analiza algunos de estos dentro de los nexos continuativos, consecutivos e ilativos, sin que resulte fácil dilucidar cuál es la frecuencia de uso de los que trata dentro de la relación de finalidad.

En nuestro corpus, solamente contabilizamos tres conectores con esta indicación, de los cuales el $98 \%$ de los usos (82 apariciones) corresponden a 'para' y 'para que'. Encontramos únicamente un ejemplo de 'con el motivo de' y uno de 'con el fin de'. En otras palabras, la poca variedad de recursos es más que evidente en este caso:

\begin{abstract}
Hoy en día, muchos conductores son tan irresponsables que a veces no se dan cuenta de las cosas que suceden a su alrededor, y no se imaginan que esas cosas le pueden suceder a ellos, por eso deben ser responsables para que el país pueda prosperar.

Desde la perspectiva económica, [la globalización] trata de lograr la integración de los mercados a escala mundial, pero, para que esto sea cierto, ha sido indispensable la formación de bloques económicos orientados bajo la lógica de libre comercio, con el fin de reproducir el capital.
\end{abstract}

\title{
3.2. Los conectores metatextuales
}

Los conectores metatextuales o metadiscursivos sirven para estructurar u organizar los constituyentes lingüísticos en el texto y para llevar a cabo reformulaciones de distintas porciones informativas (Pons 2000: 205). Siguiendo la clasificación de Portolés (2001), tendríamos tres tipos de estructuradores de la información:

Cuadro 9: Conectores de estructuración informativa (elaborado con base en Portolés 2001)

\begin{tabular}{|c|c|c|}
\hline Comentadores & Ordenadores & Digresores \\
\hline $\begin{array}{l}\text { Presentan el fragmento discursi- } \\
\text { vo como un comentario nuevo. } \\
\text { La información previa se debe } \\
\text { interpretar como una preparación } \\
\text { para la nueva porción informativa } \\
\text { o como un comentario diferente: } \\
\text { pues, bien, así las cosas, dicho } \\
\text { eso. }\end{array}$ & $\begin{array}{l}\text { Cumplen dos funciones: mostrar } \\
\text { el lugar que le corresponde a una } \\
\text { porción informativa dentro de una } \\
\text { secuencia ordenada por partes y } \\
\text { presentar dicha secuencia como un } \\
\text { comentario conformado por varias } \\
\text { secciones. Se dan tres tipos: } \\
\text { - Marcadores de apertura: en pri- } \\
\text { mer lugar, primeramente, por una } \\
\text { parte, por un lado, de una parte, } \\
\text { de un lado. } \\
\text { - Marcadores de continuidad: en } \\
\text { segundo lugar/tercer/..., por otra } \\
\text { (parte), por otro (lado), por su } \\
\text { parte, de otra (parte), de otro } \\
\text { (lado), asimismo, igualmente, de } \\
\text { igual formalmodo/manera, luego, } \\
\text { después. } \\
\text { - Marcadores de cierre: por último, } \\
\text { en último lugar, en último término, } \\
\text { en fin, por fin, finalmente, por lo } \\
\text { demás. }\end{array}$ & $\begin{array}{l}\text { Introducen un comentario lateral } \\
\text { en relación con la información dis- } \\
\text { cursiva anterior: por cierto, a pro- } \\
\text { pósito, dicho sea de paso, dicho } \\
\text { sea, entre paréntesis. }\end{array}$ \\
\hline
\end{tabular}


Calsamiglia y Tusón (2002: 246) definen estos conectores en función no de la conexión conceptual entre los enunciados, sino por su contribución al desarrollo de la enunciación. Su tipología es más precisa que la de Portolés: iniciadores (para empezar, antes que nada, primero que todo), distribuidores (por un lado, por otro; por una parte, por otra; éstos, aquellos), ordenadores (primero, en primer lugar, en segundo lugar), de transición ( por otro lado/parte; en otro orden de cosas), continuativos (pues bien, entonces, en este sentido, el caso es que, a todo esto), aditivos (además, igualmente, asimismo), digresivos (por cierto, a propósito), espacio-temporales, conclusivos (en conclusión, en resumen, en suma, en resumidas cuentas) y finalizadores (en fin, por fin, por último, para terminar, en definitiva).

Por su parte, Montolío (2001) agrupa estos conectores con los aditivos, pues ambos actúan en los textos conformando un mismo bloque temático entre la información previa y la información posterior. Sin embargo, habría que distinguir los conectores aditivos que funcionan metatextualmente y los que encuentran su razón de ser en la relación entre enunciados o porciones informativas pequeñas.

Para el habla culta costarricense, Solano (1990) consigna los conectores: 'por un lado...por otro' (1) ${ }^{16}$, 'en primer lugar' (6), 'primero' (26), 'primeramente' (3), 'por otro lado' (8), 'posteriormente' (11), 'finalmente' (8) y ‘por último' (2). La interpretación que da Solano (1990:177) a la aparición de muchos de estos conectores sin su correspondiente pareja resulta bien elocuente: "en cuanto a estas formas de distribución del discurso hay que señalar un dato que es importante con respecto a la lengua hablada, por lo menos en mis materiales. Se supone que cuando en un discurso aparece 'en primer lugar' es porque se va a hablar de otros 'lugares' que se desarrollarán posteriormente. Pero en los materiales aparece el primer término y no se va más allá. Considero que es una condición del discurso no estructurado por causa de las fragmentaciones, las interrupciones y la improvización (sic). De manera que encontramos 'por un lado' pero no aparece luego 'por otro' o 'por otro lado' como se espera de un discurso planificado. Por eso considero también que las correlaciones son tan escasas".

En nuestro corpus, de la misma manera, aparecen pocos conectores metadiscursivos. De hecho, contabilizamos ejemplos en las categorías de ordenadores y de transición, y finalizadores y de resumen, pero ningún caso de otras (v.g. digresivos). El siguiente cuadro consigna los marcadores encontrados. 
Cuadro 10: Marcadores metatextuales contabilizados en el corpus

\begin{tabular}{|l|l|l|}
\hline Marcadores de & A continuación & 1 \\
& Primen y transición & 3 \\
& Segundo & 1 \\
& Primeramente & 1 \\
Por un lado... por el & 1 \\
contrario & \\
& Por otra parte & 4 \\
Marcadores de & Por otro lado & 3 \\
conclusión y de & En segundo lugar & 1 \\
resumen & Por último & 3 \\
& En conclusión & 1 \\
& Resumiendo & 1 \\
& Ante lo anterior & 1 \\
& En fin & 2 \\
& En síntesis & 1 \\
\hline
\end{tabular}

Siguiendo a Portolés (2001), diríamos que únicamente aparecen conectores de ordenamiento, tanto de apertura como de continuación y de cierre de la información; no obstante, el recurso de señalar las porciones textuales por medio de un marcador no parece estar muy desarrollado en los estudiantes universitarios: rara vez se segmentan las porciones informativas a pesar de tratarse de textos en los que los autores exponen y argumentan sobre un tema y diversos factores o componentes relativos a este. Además, el mismo fenómeno apuntado por Solano para el discurso oral no planificado se presenta en las redacciones examinadas: aparición de un elemento ordenador sin su contraparte: por otra parte, en segundo lugar. Tampoco se echa mano de los indicadores de cierre o resumen, marcas claras de que el texto llega a su fin y que se realiza una síntesis de lo tratado.

En el siguiente fragmento, por ejemplo, se recurre al marcador 'por otro lado' sin que se evidencien, efectivamente, dos "lados" en la presentación de los problemas ocasionados por la inmigración; de hecho, pareciera haber varios "lados" (problemas) que fueron agrupados antes del conector, sin ninguna razón aparente:

Ante lo anterior no toda la población costarricense le da la bienvenida a los inmigrantes por sus implicaciones que tienen en impuestos, faltantes de cupo en el sistema educativo, demanda excesiva y largas filas para ser atendido en servicios de salud. Por otro lado la población excesiva crea una sobre oferta en mano de obra; la necesidad de trabajar por los inmigrantes casi que los obliga a trabajar por menos, cuyo resultado es el desplazamiento de la mano de obra tica (que cobra los mínimos o más) dejando parte de la oferta sin trabajar. 
En suma, en nuestra opinión, en este fenómeno se aprecia una de las características de la producción de textos escritos formales más evidentes por parte de los estudiantes universitarios: la poca o nula planificación de su escritura. Todo apunta a que el estudiante se sienta a escribir sin realizar un plan de redacción, un esquema de ideas, una estructuración temática y de porciones informativas (ejemplos, argumentos) o cualquier otra estategia de estructuración textual. Si sucediera así, sería de esperar que la organización del texto fuera más elaborada, y no una simple sucesión de elementos (argumentos, datos, referencias) sin jerarquizar, agrupar o seleccionar, como efectivamente ocurre. En otras palabras, no solo se nota la ausencia de los marcadores de estructuración informativa, sino que, con toda probabilidad, esto es una consecuencia de la falta de estructuración de los textos: los estudiantes parecen escribir según el flujo de su pensamiento, sin llevar a cabo posteriormente actividades de organización y selección del material surgido de tal flujo. Como consecuencia, las porciones informativas de sus redacciones no están en función de ninguna estrategia de presentación textual (por ejemplo, los argumentos más fuertes al principio y al final del escrito, o cada argumento debidamente enumerado para que el lector pueda seguir la línea de fundamentación sin perderse al identificar con claridad cada una de las razones aducidas); se trata, en definitiva, de una sarta de ideas sin procesar, sin dotarlas de cohesión. La siguiente redacción servirá de ejemplo para lo que acabamos de exponer:

\section{El embarazo en las adolescentes}

Hoy en día el embarazo en jóvenes y niñas es un problema presente en nuestra sociedad, es muy común buscar los culpables a este problema, pero lo importante es saber como podemos solucionarlo.

La violación es una de las razones por las que niñas y jóvenes quedan embarazadas, pero en la mayoría de los casos es la mala información que se recibe en la casa, los padres por lo general, piensan que en las escuelas y colegios se les enseña lo suficiente y se atienen a esto. Otro problema es cuando los padres dicen hablarle de sexo a sus hijos en muy pocas oportunidades mencionan lo que son los métodos anticonceptivos.

Las personas con que se convive aveces son ellas las mismas agresoras, cuando se ha sido abusada cuesta mucho que lo confiesen, en distintos casos se toma tiempo notar cambios en la conducta y mucho menos cuando los padres no le prestan mucha atención a sus hijos.

La falta de atención de los padres hacia los hijos producto del trabajo u otras razones impulsa a los adolescentes a querer pasar el día acompañados de sus amigos o alguna persona que les preste la atención que les hace falta, y los padres no se llegan a enterar de lo sucedido en todo el transcurso del día, así es como muchas jóvenes se acostumbran a hacer lo que quieran, y llegan a tener un pensamiento muy liberal, son niñas con pensamiento y comportamiento de mujeres mayores, a algunas las manipulan y cuando consiguen lo que quieren las abandonan, en el momento en que algunas de ellas quedan embarazadas llegan haber muchas reacciones, muchos buscan como corregir su error y apoyan a la mujer, otros la abandonan y no se vuelve a saber de ellos, lo que viene despúes es esperar como está la reacción de los padres si la apoyarán o no.

En los casos en que las jóvenes son abusadas sexualmente sus padres se preocupan por buscar al culpable y hacerlo pagar por lo ocurrido. La propuesta que se presento hace poco de que a una niña se le practicara un aborto fue un tema de mucha discusión a nivel nacional, su embarazo era producto de una violación, al supuesto culpable no se le pudo probar nada, sus padres querían que se le hiciera el aborto pero los médicos y las autoridades costarricenses no lo aprobaron.

Los embarazos en niñas y jóvenes entre los 11 y 18 años han aumentado considerablemente en los últimos cinco años, pero es un tema que a salido mas a la luz pública en los últimos meses. Este tema preocupa a la sociedad costarricense por que estas son niñas que tienen que se ven en la obligación de tener que dejar sus estudios para trabajar y así tener con que mantener a sus hijos. 
Las oportunidades de estudio para las madres adolescentes han ido creciendo, sean abierto sistemas de educación más fáciles como lo es Bachillerato por Madurez o a Distancia, los mismos Institutos son de gran ayuda para aquellas que por diferentes razones no pueden volver a la escuela o al colegio.

Hay que encontrar soluciones rápidas al problema de las madres adolescentes como incentivar a los padres a que hablen más con sus hijos referente a temas como la paternidad o maternidad irresponsable, en sí que temas como estos tienen que ser enseñados en los hogares y los padres no atenerse a que sus hijos aprendan en otros sitios.

\subsection{Los conectores reformuladores}

Aunque -como se señaló en 3.2.- Pons (2000) considera la función reformuladora como un tipo de operación metadiscursiva, aquí seguiremos a Portolés (2001) y, por consiguiente, separamos esta función de las tratadas en el apartado anterior. Los conectores reformuladores presentan el fragmento discursivo como una nueva expresión de lo que se dijo con anterioridad; así, sirven tanto para explicitar o concretar más la información como para rectificar los datos, el significado o, en general, la forma en que se quiere que se entienda. Portolés propone cuatro subtipos:

Cuadro 8: Conectores de reformulación (elaborado con base en Portolés 2001)

\begin{tabular}{|c|c|c|c|}
\hline Explicativos & Rectificativos & De distanciamiento & Recapitulativos \\
\hline $\begin{array}{l}\text { Aclaran o explican la } \\
\text { porción informativa } \\
\text { previa: o sea, es decir, } \\
\text { esto es, a saber, en otras } \\
\text { palabras, en otros térmi- } \\
\text { nos, dicho con/en otros } \\
\text { términos, con otras pala- } \\
\text { bras, dicho con/en otras } \\
\text { palabras, dicho de otra } \\
\text { manera/modolforma, de } \\
\text { otro modo. }\end{array}$ & $\begin{array}{l}\text { Presentan el fragmen- } \\
\text { to informativo ante- } \\
\text { rior como incorrecto o } \\
\text { inexacto y lo reemplazan } \\
\text { por una nueva formu- } \\
\text { lación mejorada: mejor } \\
\text { dicho, más bien. }\end{array}$ & $\begin{array}{l}\text { Indican que el fragmento } \\
\text { anterior no es relevante } \\
\text { para la continuación del } \\
\text { texto, sino que para tal } \\
\text { efecto debe tomarse en } \\
\text { cuenta la porción infor- } \\
\text { mativa introducida por } \\
\text { el conector: en cualquier } \\
\text { caso, en todo caso, de } \\
\text { todos modos, de todas } \\
\text { formas, de todas mane- } \\
\text { ras, de cualquier modo, } \\
\text { de cualquier formal } \\
\text { manera. }\end{array}$ & $\begin{array}{l}\text { Muestran una conclusión } \\
\text { o recapitulación de lo } \\
\text { dicho: } \\
\text { - Con la misma orienta- } \\
\text { ción: en suma, en con- } \\
\text { clusión, en resumen, en } \\
\text { síntesis. } \\
\text { - Con una orientación } \\
\text { opuesta: en resumidas } \\
\text { cuentas, en definitiva, a } \\
\text { fin de cuentas, en fin, } \\
\text { total, al fin y al cabo, } \\
\text { después de todo. }\end{array}$ \\
\hline
\end{tabular}

En las redacciones estudiadas, nos concentramos en los conectores explicativos y rectificativos, pues los recapitulativos se trataron en el apartado 3.2.; en cuanto a los de distanciamiento, estas marcas no interesaban para los fines de este trabajo, por ello mismo también se dejaron de lado. Básicamente, en las sesenta redacciones analizadas, únicamente se encontraron tres conectores explicativos: es decir (4 apariciones), en otras palabras y osea (sic), estos últimos cada uno con una aparición. En los rectificativos, solamente aparece mejor dicho una vez. Por lo tanto, se hace poco uso de estas funciones discursivas dirigidas a aclarar el contenido de lo expuesto y la interpretación que debe dársele a un argumento: 


\begin{abstract}
Fundamentando su odio y repulsión en superfluas razones inexistentes, cimentadas en un acaparamiento del mercado laboral, es decir, los puestos de trabajo son para emigrantes por que aceptan un salario mas bajo.

Si la gente no entiende con publicidad ecologista, la única manera de hacer entender será emitiendo multas, osea hacer una política ambientalista actual (...)

Muchos jóvenes en vez de sacar una carrera y un titulo, escogen la salida más facil. El robo, la venta ilegal, un trabajo de poco esfuerzo, etc. En otras palabras, nos gusta el dinero facil.
\end{abstract}

Llama la atención que, en los datos de Solano (1990) sobre el discurso oral espontáneo, o sea aparezca como el nexo por excelencia para expresar esta operación (248 apariciones), seguido de lejos por es decir (53 apariciones), digo (9), mejor dicho (1), dicho de otro modo (1) y en otras palabras $(1)^{18}$. Esto es, la operación discursiva de la que hablamos sí resulta ser frecuente en el habla. Quizás en este aspecto los estudiantes no recurran a un marcador como 'o sea' al escribir por formar parte este de su repertorio de elementos discursivos orales que afloran sin mucho control en el habla planificada sobre la marcha, de lo cual podrían tener una conciencia incipiente.

\title{
3.4. Los operadores discursivos
}

Dentro de esta categoría, Portolés (2001) incluye los conectores que no relacionan, por su significado, la porción informativa en la que aparecen con la anterior, sino que condicionan sus posibilidades discursivas. La definición de Calsamiglia y Tusón (2002: 247) resulta más esclarecedora: “(...) se trata de elementos que en general se sitúan en posición inicial de enunciado, o como preámbulo al segundo miembro de la relación. Estos procedimientos o bien indican la posición del Enunciador ante su enunciado o bien orientan hacia un tipo concreto de tratamiento de la información". Para los fines de este trabajo, nos interesan dos de los subtipos tratados por Portolés (2001), al que le agregamos uno de los incluidos por Calsamiglia y Tusón (2002).

\section{Cuadro 9: Operadores discursivos}

\begin{tabular}{|c|c|c|}
\hline De refuerzo argumentativo & De concreción o ejemplificación & De tematización o topicalización \\
\hline $\begin{array}{l}\text { Refuerzan la porción informativa } \\
\text { en la que aparecen frente a otros } \\
\text { argumentos: en realidad, en el } \\
\text { fondo, en rigor, de hecho, en efec- } \\
\text { to, la verdad, desde luego, por } \\
\text { supuesto. }\end{array}$ & $\begin{array}{l}\text { Concretan o ejemplifican una } \\
\text { generalización previa: por ejem- } \\
\text { plo, verbigracia, en especial, en } \\
\text { particular, en concreto, a saber, } \\
\text { pongamos por caso, sin ir más } \\
\text { lejos. }\end{array}$ & $\begin{array}{l}\text { Muestran la topicalidad de un frag- } \\
\text { mento informativo: respecto a, a } \\
\text { propósito de, por lo que respecta } \\
a \text {, en cuanto a, referente a, con } \\
\text { referencia, en lo que concierne, } \\
\text { en/por lo que se refiere a }\end{array}$ \\
\hline
\end{tabular}

En cuanto a los operadores de concreción o ejemplificación, el elemento más empleado es 'por ejemplo' (14 apariciones). Aparte aparecen, en mucha menor cuantía, otros marcadores: así (4), tal (y) como (3), como lo son (3), tales como (2). En el habla culta costarricense, por su parte, Solano (1990) consigna únicamente el operador por ejemplo (169 apariciones) ${ }^{19}$, lo cual demuestra que incluso en el discurso espontáneo oral es el más frecuente. 
Pese a que la operación discursiva de la concreción reviste un carácter fundamental en los textos expositivo-argumentativos como los tratados en este estudio, los estudiantes hicieron poco uso de los recursos disponibles para tal efecto. En otros términos, algunas veces no recurrieron a la estrategia de pasar de lo abstracto y general a lo concreto y particular cuando así lo ameritaba el tratamiento del tema, con el fin de ayudarle al lector en su proceso de asimilación y procesamiento de la información. Tampoco los nexos de refuerzo se emplearon mucho; únicamente se encontraron los conectores 'claro' (3), 'claro está' (1) y 'sobre todo' (1).

Con respecto a los operadores de tematización o topicalización, contabilizamos tres de ellos: en cuanto a (3 apariciones), en el caso de (1), en relación con (1) y su variante con relación a (1):

En cuanto a la madre, que si no decide abortar a su hijo poniendo en peligro hasta su vida misma, decide tenerlo (...)

Se puede entender la identidad como el factor o conjunto de factores que caracterizan y diferencian a una persona o cosa de las demás. En el caso de un país, la identidad nacional es el conjunto de características, condiciones y manifestaciones sociales, políticas, económicas y culturales que lo diferencia y lo particulariza del resto de las naciones del mundo.

\section{Conclusión}

Los mecanismos de cohesión son marcas formales que se reconocen como tales. En este sentido, se ha señalado la existencia de una serie de recursos especializados para mostrar la relación entre los diversas porciones informativas de los textos (orales o escritos); es decir, elementos de cohesión textual: los conectores discursivos. A este respecto, es fundamental tener en mente la aclaración de Pons (2000: 213): "Cuando se clasifica un conector como correlativo, adversativo o consecutivo no se debe interpretar que todos sus usos se pueden encuadrar dentro de dicha función, sino más bien que, en dicha clasificación, se recoge la mayor parte de sus apariciones". Por ello mismo, debe entenderse que los cuadros de conectores que presentamos responden -a nuestro entender- a una categorización de la función nexual prototípica de cada uno, lo cual no equivale a afirmar que esa sea su única función discursiva.

Como hemos visto, la principal característica de las redacciones estudiadas, en relación con el empleo de los conectores discursivos, es la subutilización de tales recursos de cohesión textual. En general, para cada categoría, existe un repertorio conformado por varios elementos cercanos en cuanto a la indicación de procesamiento que proveen; no obstante, los estudiantes universitarios echaron mano de muy pocos de ellos. En no pocas ocasiones, se recurrió prácticamente a un solo conector de la categoría para expresar la mayoría de las relaciones discursivas del mismo tipo (v.g. pero, por ejemplo, para que).

Generalmente, los conectores usados son, asimismo, los más frecuentes en el discurso oral espontáneo costarricense, en la llamada habla culta. A este respecto, parece que la hipótesis de Rodino y Ross (1985) sobre la transferencia de los recursos propios del registro oral al registro escrito parece verse corroborada en nuestro estudio. Dicha propuesta afirma que la indiferenciación de patrones propios de la oralidad no planificada y de la escritura planificada es una de las características más claras de los problemas de redacción por parte de los estudiantes costarricenses. 
Sin embargo, también se presenta un fenómeno opuesto: la sobreutilización, en los escritos, de recursos escasamente empleados en el habla, como muestra de una especie de conciencia incipiente de separación de los elementos específicos o más frecuentes de la escritura frente a la oralidad, tal es el caso de la operación causativa con el conector 'ya que'.

A todas luces, el descuido en el tratamiento de estas marcas de cohesión patente en los libros de enseñanza de la expresión escrita y, en general, en las clases de lengua materna requiere un cambio, no solo por una preocupación de estilo (variar los conectores para expresar la misma noción en un mismo texto), sino, especialmente, porque el problema de fondo consiste en un problema de cohesión de las porciones informativas de los escritos, lo que implica deficiencias en el establecimiento claro de las relaciones lógicosemánticas entre los enunciados, en la estructuración y jerarquización de los segmentos textuales y, en definitiva, en la señalización de cómo debe interpretarse, procesarse y recordarse la información.

\section{Notas}

1. Así, el ejemplo de uso incorrecto en este caso es el siguiente: "Por ningún motivo debe permanecer, ni pasear en los corredores", que debe sustituirse por: "Por ningún motivo deben permanecer o pasear en los corredores". Como se puede apreciar, se confirma la manera caprichosa y acientífica con la que se llevó a cabo el análisis en dicha tesis.

2. Enlaces extraoracionales, conectores, conectores extraoracionales, conectores pragmáticos, conectores discursivos, conectivos, partículas discursivas, enlaces textuales, operadores discursivos, marcadores del discurso, mecanismos de señalización discursiva, conectivos fáticos, expresiones pragmáticas, conectivos oracionales, etc. (Portolés 2001, Martín Zorraquino 1999, Montolío 2001, Fraser 1999).

3. A este respecto, valga mencionar también que, en algunos casos, se hará caso omiso de las restricciones impuestas por un determinado investigador sobre lo que constituye o no un conector, con el fin de preservar el tono práctico de nuestro estudio.

4. Al igual que Fraser (1999), recurro a una noción general y poco precisa en términos sintácticos para referirme a los segmentos conectados. Fraser (1999: 938) emplea el término 'segmento discursivo' para cubrir nociones como ‘proposición', ‘enunciado’ y 'mensaje'. Yo hago lo mismo con el término utilizado por él y con otros como 'porción informativa' o 'segmento textual'.

5. Una recopilación bastante exhaustiva de diversas tipologías y repertorios de nexos discursivos se puede encontrar en el proyecto de graduación de Quirós Leiva (2004).

6. La proposición es la unidad básica de almacenamiento informativo significativo en la memoria de largo plazo; el significado oracional y de los párrafos se puede establecer en forma de red de proposiciones (McCabe 1999).

7. Montolío trata en la misma sección los conectores aditivos y los organizadores de la información. Nosotros, siguiendo a Portolés (2001) y a Calsamiglia y Tusón (2002), preferimos tratarlos por aparte; de ahí que hayamos modicado el cuadro de Montolío (2001) al excluir de él los conectores organizadores. 
8. Para las referencias sobre el habla culta costarricense, seguimos a Solano Rojas (1990). Hay que aclarar, sin embargo, que realizamos cambios importantes en la nomenclatura y la concepción con las cuales esta lingüista presenta los conectores discursivos, por cuanto estas corresponden, en su estudio, a la perspectiva de la gramática tradicional, no de la lingüística textual. Por ejemplo, Solano habla en este caso de nexos copulativos, en los que incluye 'y' y 'ni', pero trata formas como 'además' dentro de los nexos continuativos.

9. Sin embargo, los trabajos sobre otros idiomas sí incluyen el equivalente de 'y' dentro de esta categoría (Brown y Yule 1993, van Dijk 1993).

10. Tomo los ejemplos tal y como los consigna Solano (1990) en su estudio.

11. Dicha selección se basa en la naturaleza de los elementos conectados; es decir, se contabilizaron los casos en los cuales ' $y$ ' enlazaba unidades textuales mayores (párrafos y enunciados), pero no frases.

12. Este total incluye las dos apariciones de 'e', el cual, a fin de cuentas, representa un alomorfo de 'y' condicionado fonológicamente.

13. Esta es la hipótesis que subyace a todo el análisis de Rodino y Ross (1985) sobre los problemas de expresión escrita de los estudiantes universitarios costarricenses.

14. Nuestros datos únicamente confirman lo que es, desde hace mucho, una impresión del autor de este artículo y de muchos otros profesores: en los textos escritos por los estudiantes costarricenses, el conector 'ya que' aparece indiscriminadamente.

15. Este uso masivo de únicamente el conector 'ya que' no es aislado; se encuentran, asimismo, textos con seis o más apariciones de este nexo y ningún otro.

16. El número entre paréntesis después del conector señala la frecuencia absoluta de apariciones. No consignamos la frecuencia relativa debido a que la autora trata en el mismo apartado otros nexos pertenecientes a otras categorías.

17. Este conector, bastante atípico, parece tener, en el texto en el cual aparece, el valor del conclusivo 'en fin': "Hay que encontrar soluciones rápidas al problema de las madres adolescentes como incentivar a los padres a que hablen más con sus hijos referente a temas como la paternidad o maternidad irresponsable, en sí que temas como estos tienen que ser enseñados en los hogares y los padres no atenerse a que sus hijos aprendan en otros sitios."

18. De nuevo, las agrupaciones de Solano no corresponden con las nuestras. Ella trata en la sección de nexos explicativos los conectores señalados así como el operador 'por ejemplo' (de concreción, en nuestro marco teórico), razón por la cual prescindimos de los porcentajes de frecuencia de aparición dados por esta lingüista.

19. En realidad es el único conector de este tipo que corresponde con la clasificación que manejamos en este estudio. Al respecto véase la nota anterior. 


\section{Bibliografía}

Anscombre, Jean-Claude y Oswald Ducrot. 1994. La argumentación en la lengua. Madrid: Editorial Gredos.

Berko Gleason, Jean y Nan Bernstein Ratner. 1999. Psicolingüística. Madrid: McGrawHill.

Bosque, Ignacio y Violeta Demonte. 1999. Gramática descriptiva de la lengua española. V. 3. Madrid: Espasa Calpe.

Briz, Antonio y Grupo Val.Es.Co. 2000. ¿Cómo se comenta un texto coloquial? Barcelona: Ariel.

Brown, Gillian y George Yule. 1993. Análisis del discurso. Madrid: Visor Libros.

Calsamiglia Blancafort, Helena y Amparo Tusón Valls. 2002. Las cosas del decir. Manual de análisis del discurso. Barcelona: Ariel.

Cassany, Daniel. 1995. La cocina de la escritura. Barcelona: Anagrama.

De Beaugrande, Robert-Alain y Wolfgang Ulrich Dressler. 1997. Introducción a la lingüística del texto. Barcelona: Ariel.

Fraser, Bruce. 1999. “What are discourse markers?”. Journal of Pragmatics 31, 931-952.

Lozano, Jorge, Cristina Peña-Marín y Gonzalo Abril. 1999. Análisis del discurso. Hacia una semiótica de la interacción textual. Madrid: Cátedra.

Martin Zorraquino, María Antonia y José Portolés Lázaro. 1999. "Los marcadores del discurso". En: Bosque y Demonte (ed.).

McCabe, Allyssa. 1999. “Oraciones combinadas: texto y discurso”. En: Berko y Bernstein (ed.).

Montolío, Estrella. 2000. “La conexión en el texto académico. Los conectores”. En: Montolío (coord.).

(coord.). 2000. Manual práctico de escritura académica. Volumen II. Barcelona: Ariel.

2001. Conectores de la lengua escrita. Barcelona: Ariel.

Pons Bordería, Salvador. 2000. "Los conectores”. En: Briz y Val.Es.Co. 
Portolés, José. 2001. Marcadores del discurso. Barcelona: Ariel.

Quesada Bogantes, Auxiliadora y Marta Isabel Ramírez Bogantes. 1993. Análisis de expresión escrita de los directores de centros educativos. Tesis de Licenciatura en Ciencias de la Educación con énfasis en Administración Educativa, Universidad de Costa Rica.

Quirós Leiva, Dennis. 2004. El esquema. Didáctica de la Redacción. Proyecto de graduación para el grado de Licenciado en Ciencias de la Educación con énfasis en Docencia, UNED.

Rodino, Ana María y Ronald Ross. 1985/2001. Problemas de Expresión Escrita del Estudiante Universitario Costarricense. Un estudio de lingüística aplicada. San José: EUNED.

Rodino Pierri, Ana María. 1988. Las modalidades discursivas fragmentación e integración en el discurso oral y escrito del español costarricense escolarizado. Tesis de Maestría en Lingüística, Universidad de Costa Rica.

Sánchez Avendaño, Carlos. 2004a. "Historiografía de la enseñanza de la redacción en Costa Rica: los libros de texto". Revista de Filología y Lingüística XXX (1): 219-246.

2004b. "La puntuación y las unidades textuales: Una perspectiva discursiva para el estudio de los problemas de su uso y para su enseñanza". Revista Educación (en prensa).

Solano Rojas, Yamilet. 1990. Los nexos en el habla culta costarricense. México. Tesis para optar al grado de doctora en Letras con especialidad en Lingüística Hispánica, Universidad Autónoma de México.

Van Dijk, Teun. 1993. Texto y contexto (Semántica y pragmática del discurso). Madrid: Cátedra. 